\title{
Effects of Lactobacillus used as the starter culture on naturally fermented pickled cabbage
}

\author{
Yusuf ALAN ${ }^{1^{*}}$ (D), Neslihan YILDIZ²
}

\begin{abstract}
Pickled cabbage is a traditional and typical fermented food, which occurs as a result of fermentation of bacteria that exist in the medium naturally. In this study, the effects of Lactobacillus plantarum, Lactobacillus pentosus and Lactobacillus paraplantarum on the pickled cabbage fermentation were investigated. The physicochemical (total acidity, salt and $\mathrm{pH}$ ) and microbiological (lactic acid bacteria, total mesophilic aerobic bacteria and yeast-mould) changes that occurred during the fermentation were observed. In addition, the amounts of biogenic amine (BA) and metabolites were determined with HPLC. It was found that the amount of acidity (\%) was lower in Lactobacillus samples. Important microbiological changes were observed in the L. plantarum 46 and $L$. pentosus samples. The total BA amount was found to be the lowest for the sample $L$. plantarum 61 . It was also seen that the BA was less than any poisonous rate affecting the human health. On day 60 of fermentation, the amount of metabolite was maximum in the L. plantarum 61 and $L$. paraplantarum samples. As a result, the total amount of BA was observed to be lowest in the L. plantarum 61 sample inoculated with L. plantarum 61 culture and in the metabolites synthesized highly. It is suggested that the use of such Lactobacillus for the natural pickle process will allows for the production of a tastier and more reliable product, contributing to the food industry.
\end{abstract}

Keywords: Lactobacillus; pickled cabbage; metabolite; biogenic amines; HPLC.

Practical Application: The effects of Lactobacillus strains used as starter culture in terms of microbiological, physicochemical, biogenic amine and metabolite contents in pickled cabbage.

\section{Introduction}

Cabbage is a vegetable that is rich in minerals, vitamin C, dietary fibers and phytochemicals (Yoon et al., 2006). Traditionally, naturally fermented cabbage products are cultivated all over the world, and are called under various local names like Pao Cai, Kimchi and Sauerkraut (Plengvidhya et al., 2007). Sauerkraut is an important fermented cabbage product, and is also a way to keep cabbage for a long time (Trail et al., 1996).

Pickled cabbage fermentation is the result of the spontaneous lactic acid production of lactic acid bacteria (LAB) in the presence of favorable temperature and salt in the anaerobic environment. LABs are used commonly as a starting culture in the production of fermented foods and cause important changes in nutritional, organoleptic and physicochemical characteristics of foods (Sáez et al., 2018). LABs, which are dominant in the medium in pickle fermentation are Leuconostoc mesenteroides, Enterococcus faecalis, Lactobacillus brevis, Lactobacillus pentosus, Pediococcus pentosaceus and Lactobacillus plantarum. Since L. plantarum has a higher acid tolerance than other LAB, it is the bacterium that completes fruit and vegetable fermentation (Di Cagno et al., 2013). Starter cultures of L. plantarum and L. mesenteroides affect the quality of sauerkraut in low salt environments (Zubaidah et al., 2020).

The reliability and quality of fermented foods has attracted public interest in many parts of the world, and the focus has been

on scientific studies to minimize the risks that are associated with potentially unhealthy food components (Wu et al., 2014). The LABs that contribute to the quality of the food at a significant level use the Embden-Meyerhoff-Parnas (EMP) Pathway and produce nutrient metabolites like formic acid, lactic acid, ethanol, acetic acid, amino acids, acetoin, mannitol and 2.3-butanediol (Jo et al., 2015). Biogenic amines (BA), which are also important for food safety, are basic nitrogenous compounds formed with the transamination of aldehyde and ketones or with the decarboxylation of some specific amino acids in foods (Maijala et al., 1995). Storage of foods in unfavorable media (temperature, $\mathrm{pH}$, carbon sources, aerobic or anaerobic conditions) and the interaction of the starter cultures that are employed in fermented foods with normal microbial flora in food, is effective in the formation of BAs and metabolites (Liu et al., 2017).

In this study, our purpose was utilizing Lactobacillus by way of a starter-culture to make customary pickled cabbage. The physicochemical and microbiological changes were observed during the fermentation. As a result of the changes caused by starter cultures because of outside influences (salt, $\mathrm{pH}$, microbial flora and acidity), the amounts of BAs and metabolites, which are important for food safety and quality, were determined with the High-Performance Liquid Chromatography (HPLC). 


\section{Materials and methods}

\subsection{Materials}

The hybrid Megaton cabbages (Brassica olerace) that were used in pickle making were obtained from the city of Afyonkarahisar in Turkey. As the starter culture, five Lactobacillus strains (L. plantarum 8, L. plantarum 46, L. plantarum 61, L. paraplantarum and $L$. pentosus) whose functional features had been determined in our previous studies (BA, antibiotic resistance and synthesis, and metabolite amount, etc.) were used (Alan, 2015; Alan et al., 2018).

\subsection{Starter culture preparation}

Lactobacillus strains (L. plantarum 8, L. plantarum 46, L. plantarum 61, L. paraplantarum and L. pentosus) were prepared according to Alan, (2019). LAB isolates were cultured at MRS broth $37^{\circ} \mathrm{C} 18$ hours. Every individual $10 \mathrm{~mL}$ cultured isolates were centrifuged for $20 \mathrm{~min}, 4500 \mathrm{rpm}$ and cell pellets were obtained. Washing of the cell pellets were done with $0,85 \%$ $\mathrm{NaCl}$, and washing was done two times. After washing, the stock culture was prepared by placing the cells in $10 \mathrm{~mL}$ sterile $0.85 \%$ $\mathrm{NaCl}$ medium with a cell density of 9-LogCFU / mL.

\subsection{Preparing the pickled cabbage}

The pickled cabbage samples were made by using the LAB whose functional features were found. The pickles were made with 7 different trials encoded as follows: Control (salt $(\mathrm{NaCl})), \mathrm{L} 2$ (L. plantarum $8+$ salt), L3 (L. plantarum $46+$ salt), L4 (L. plantarum $61+$ salt), L5 (L. pentosus + salt), L6 (L. paraplantarum + salt) and $\mathrm{L} 7($ salt + vinegar $(15 \mathrm{~mL}))$. The cabbages that were washed and dried were made into small pieces; and $35 \mathrm{~g}$ (5\%) rock salt was added to $700 \mathrm{~g}$ cabbage, and after thoroughly blending, placed inside $1.3 \mathrm{~L}$ pickle vessels. Prepared cabbage was inoculated with different starter culture (L. plantarum, L. pentosus and L. paraplantarum) at a rate of $1 \%(\mathrm{v} / \mathrm{w})$. Pickle containers were stored for 60 days at $20-25{ }^{\circ} \mathrm{C}$. During the fermentation, the $\mathrm{pH}$, titration salt (\%), acidity (\%) together with micro-biological analyzes (total LAB, total yeast-mould count and total mesophilic aerobic bacteria) were carried out. Microbiological changes were observed in the pickled samples on days 15, 30 and 60. In addition, the biogenic amine and metabolite amounts were found with a HPLC on days 30 and 60 of fermentation. In this study, the pickle trials were made in three repetitions.

\subsection{Determination of the total acidity, salt ( $\mathrm{NaCI}$ ) and $\mathrm{pH}$}

Nine (9) $\mathrm{mL}$ of distilled water was added to the $1 \mathrm{~mL}$ brine samples to determine the titration acidity. Then, together with $1 \%$ phenolphthalein indicator (Merck, Germany), and with adjusted $0.1 \mathrm{~N} \mathrm{NaOH}$ (Merck, Germany) solution, the samples were titrated until a slight pink color was formed, and the amount of alkali was recorded. The overall acidity was found as percentages of acetic and lactic acids. $\mathrm{pH}$ levels of brines were found with the help of a $\mathrm{pH}$ Meter $(\mathrm{HACH}, \mathrm{HQd}$ Field Case, USA) that was calibrated by using $\mathrm{pH} 4.1,7.0$ and 10.1 standard buffers. The salt amounts inside the brine were found with the
Mohr Method. Accordingly, $1 \mathrm{~mL}$ brine samples were diluted with $9 \mathrm{~mL}$ distilled water. Following this, $1 \mathrm{~mL}$ of $5 \%$ potassium dichromate solution $\left(\mathrm{K}_{2} \mathrm{CrO}_{4}\right)$ (Merck, Germany) was put into the dilution and titrated adjusted $0.1 \mathrm{~N} \mathrm{AgNO}_{3}$ solution (Merck, Germany) till the colour turned tile red. $\mathrm{AgNO}_{3}$ solution volume was logged, and the total quantity of salt was calculated as a percentage (Alan, 2019).

\subsection{Microbiological analyses}

Total mesophilic aerobic bacteria count, Plate Count Agar (PCA) and LAB count were performed according to the spread cultural counting method in the De Man, Rogosa and the Elisabeth Sharpe (MRS) broth medium (Xiong et al., 2016). The colonies were counted by incubating the samples at $37^{\circ} \mathrm{C}$ for 24-48 hours. The yeast-mould count done with the Potato Dextrose Agar (PDA) broth medium according to spread cultural counting method. Colony counts was carried out by incubating the samples for $48-72$ hours at $25^{\circ} \mathrm{C}$. The units that formed colony were measured in Log CFU/g. Proper decimal dilutions were prepared by using isotonic solution $(0.85 \% \mathrm{NaCl})$ for cell counting (Alan, 2019).

\subsection{Determination of biogenic amine}

The final histamine, putrescine, cadaverine, tyramine and spermidine BA concentrations were weighed $1 \mathrm{mg} / \mathrm{mL}$, and were dissolved in $0.4 \mathrm{M}$ of perchloric acid $\mathrm{HClO}_{4}$ (Sigma-Aldrich, USA) separated into $10 \mathrm{~mL}$ aliquot tubes to prepare the main standard stock. A total of $5 \mathrm{~mL}$ stock solution for each of the BAs were diluted by $0.4 \mathrm{M} \mathrm{HClO}_{4}$ to prepare the standard solution at different concentrations. Every one of the standard stock solutions were prepared in six different dilutions into 5, 10, 25, 50,75 and $100 \mathrm{ppm}$; and $10 \mathrm{~g}$ of pickled vegetables, together with $10 \mathrm{~mL}$ brine was reserved from the pickle samples and were homogenized (IKA T18 D Ultra Turrax, Germany). Two $2 \mathrm{~mL}$ homogenate was obtained and put in $10 \mathrm{~mL}$ falcon tubes; and $5 \mathrm{~mL} 0.4 \mathrm{M} \mathrm{HClO}_{4}$ were put in shaken for 60 minutes; and was then made into $10 \mathrm{~mL}$ through $5 \%$ trichloroacetic acid (Sigma-Aldrich, USA). Then, for derivatization, $400 \mu \mathrm{L}$ of the solution that was formed from the extract transferred to $10 \mathrm{~mL}$ falcon tubes with lids that were encased in aluminum foil beforehand. The dansyl chloride, sodium glutamate and sodium carbonate (Sigma-Aldrich, USA) that were used in derivatization was formulated daily. The supernatant stage that was acquired in derivatization was filtrated with filters having $0.45 \mu \mathrm{m}$ pore diameters and were moved to eppendorf tubes being stored at $-20^{\circ} \mathrm{C}$ pending HPLC analysis. Mobile stage, $30 \mathrm{~mL}$ buffer $(0.1 \mathrm{M}$ Tris, $0.1 \mathrm{M}$ acetic acid and pure water at a rate of $2,1,2$, respectively), $420 \mathrm{~mL}$ pure water and $550 \mathrm{~mL}$ acetonitrile were used for Solvent A; and $2 \mathrm{~mL}$ buffer, $900 \mathrm{~mL}$ acetonitrile, $100 \mathrm{~mL}$ pure water were used for Solvent B (Alan, 2019; Alan et al., 2018).

\subsection{Determining the amounts of the fermentation metabolites}

Preparation of stock standards was done by weighing finalized concentrations of 2.3-butanediol, pyruvate, lactate, 
ethanol, acetoin, hydrogen peroxide $\left(\mathrm{H}_{2} \mathrm{O}_{2}\right)$, and acetic acid standards $1 \mathrm{mg} / \mathrm{mL}$, and liquefying in $10 \mathrm{~mL}$ falcon tubes $0.5 \%$ metaphosphoric acid (MPA). Four different dilutions (50, 100, 150 and $200 \mathrm{ppm}$ ) of the stock standards were made loaded into HPLC apparatus. $10 \mathrm{~mL}$ brine and $10 \mathrm{~g}$ vegetable juice were sampled from each pickle sample and were homogenized; and $5 \mathrm{~mL}$ was taken from the homogenate and placed into $10 \mathrm{~mL}$ falcon tubes and were centrifuged for $5 \mathrm{~min}$ at $8000 \mathrm{rpm} .1 \mathrm{~mL}$ supernatant taken and transferred to eppendorf tube with $1 \mathrm{~mL}$ $1 \%$ MPA. Following this the tube was vortexed at $12000 \mathrm{rpm}$ for $2 \mathrm{~min} \mathrm{rpm}$. The supernatant went through $0.45 \mu \mathrm{m}$ pore diameter filters and $0.5 \mathrm{~mL}$ was moved into vials. After, samples were loaded into the HPLC device to determine in order to find metabolites within supernatants. At carrier phase, 0.5\% MPA was employed (Alan, 2019; Alan et al., 2018).

The Agilent Technologies 1260 InfinityII HPLC Device (Agilent, USA) is employed for BA and metabolite analyses. The HPLC was configured to 1260 DAD WR detector (BA; $254 \mathrm{~nm}$, and metabolites at 192 and $210 \mathrm{~nm}$ wavelengths), 1260 Quat Pump VL pump (BA; $1.3 \mathrm{~mL} / \mathrm{min}$ and metabolites $1 \mathrm{~mL} / \mathrm{min}$ flow rate), 1260 Vialsampler (20 $\mu \mathrm{L}$ injection) and G7130A column oven $\left(28^{\circ} \mathrm{C}\right)$. Analytical column for analysis was ACE5 C18 (250x4.6 mm id).

\subsection{Statistical analysis}

Statistical analysis was carried out by employing GraphPad Prism 8 Software, together with Dunnett and Tukey Tests. Average values $(\mathrm{n}=3)$ were calculated by \pm standard deviations. Two-Way (ANOVA) Variance Analysis were carried out on data that were collected throughout fermentation. Variances were considered significant at $\mathrm{p}<0.05$.

\section{Results and discussion}

\subsection{Changes in pH, titration acidity, and salt values}

Pickles prepared by adding starter cultures significant changes were observed in acetic acid \%, lactic acid \%, pH and salt amount from the first day of fermentation to the $60^{\text {th }}$ day (Figure 1). The number of LABs and the amount of organic acids increased depending on the progress of the fermentation time. As a result of this situation, it was determined that the $\mathrm{pH}$ decreased due to the increase in the acidity of the environment.
A
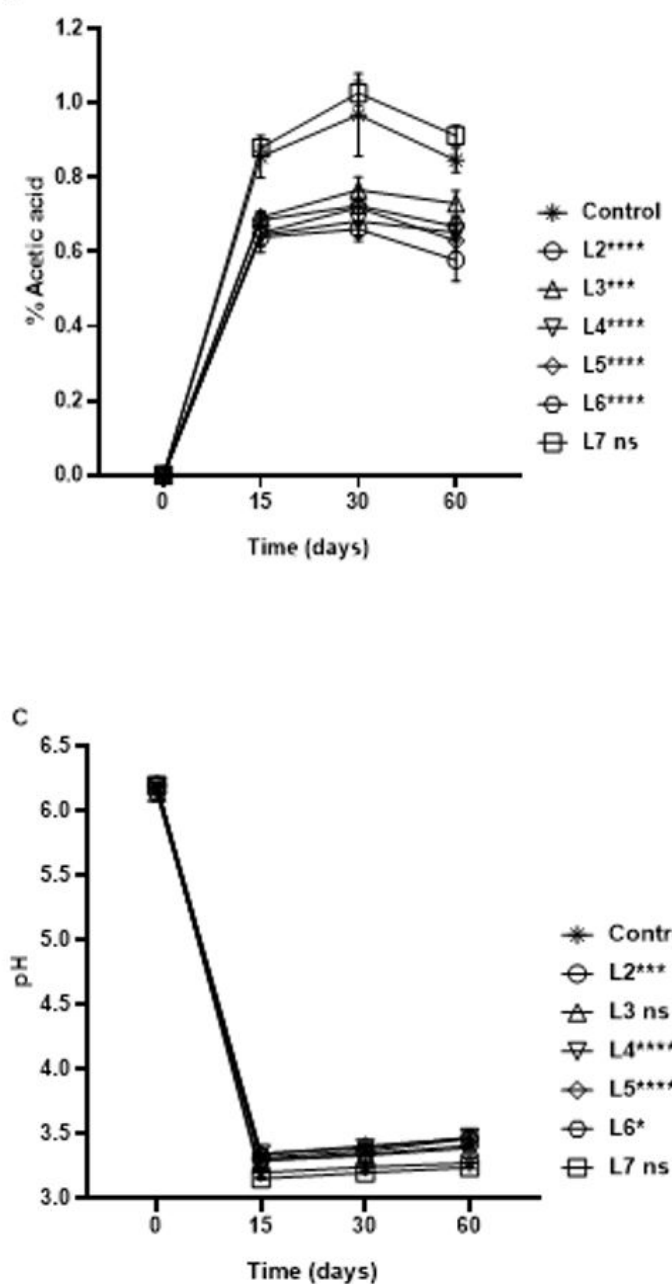

B

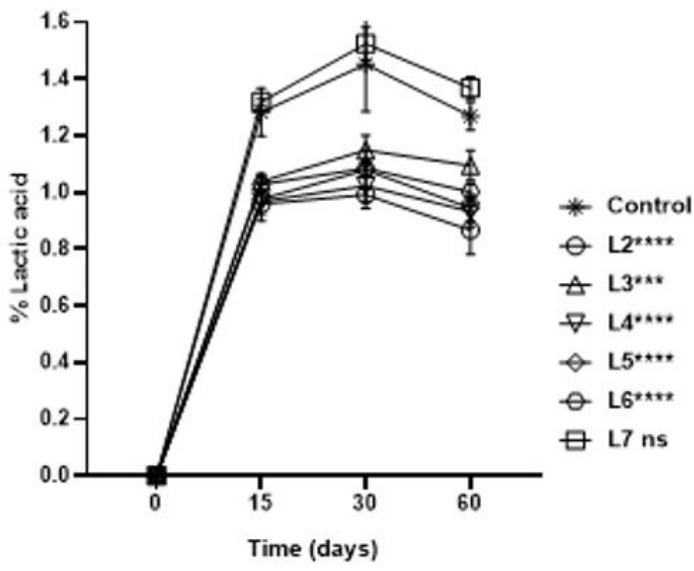

D

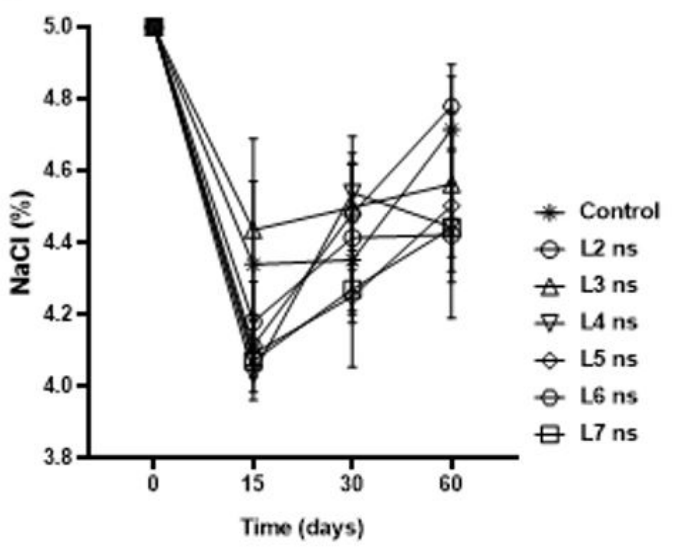

Figure 1. The changes in the acetic acid (A), lactic acid (B), $\mathrm{pH}(\mathrm{C})$ and salt (D) rates in pickled cabbage fermentation. 
It was determined that the percentage lactic acid and acetic acid ratios of cabbage pickles during fermentation increased until the $30^{\text {th }}$ day and decreased to the levels of the $15^{\text {th }}$ day on day 60 (Figure 1). When compared to pickled cabbage that was made for control purposes, it was detected that the samples L2, L4, L5 and L6 had significant differences $(\mathrm{p}<0.0001)$. It was observed that acidity increased with the progress of fermentation in Chinese cabbage pickle samples fermented by Lactobacillus, which are homo-fermentative LAB starter in a previous study (Zhao et al., 2018). It was reported that the titratable acidity shows a fast increase at the beginning of fermentation and stabilizes in the next days (Nilchian et al., 2016). On the other hand, in our study, it was observed that acidity rapidly increase occurred until the $15^{\text {th }}$ day of fermentation and stabilized with the prolongation of the fermentation period.

It was observed that in the pickled cabbages made with $5 \%$ salt, the quantity of salt decreases rapidly until the $15^{\text {th }}$ day, but increases after the $15^{\text {th }}$ day. No significant differences were detected between the samples (Figure 1). During fermentation, a fast reduction in $\mathrm{pH}$ was observed in all pickle samples until the first $15^{\text {th }}$ day. During the later periods of fermentation, the $\mathrm{pH}$ remained stable. It was determined that the L4 and L5 samples showed a highly significant difference $(\mathrm{p}<0.0001)$ (Figure 1$)$.
It is reported that the use of LABs in pickle production reduces the growth of unwanted microorganisms in the medium by causing a rapid decrease in $\mathrm{pH}$ at the beginning of fermentation (Pistarino et al., 2013). It was also indicated that LABs gradually decrease the $\mathrm{pH}$ in sauerkraut fermentation until they reached a proper level (Tolonen et al., 2004). In preceding research were reported that the $\mathrm{pH}$ values reduce rapidly at the beginning and then gradually reach a steady level (Nilchian et al., 2016; Xiong et al., 2014). The results we have obtained are similar to the studies conducted. The decrease in $\mathrm{pH}$, which is an important indicator of the progress of fermentation, is related to the amount of lactic acid formed as a result of the metabolism of LABs (Adams, 1990). According to our results, it was determined that as the amount of lactic acid increased, the $\mathrm{pH}$ decreased at a similar rate.

\subsection{Microbiologic changes}

It was determined that the number of microorganisms (LAB, total mesophilic aerobic bacteria and yeast-moulds) at the beginning of the pickled cabbage fermentation increased until the $15^{\text {th }}$ day of fermentation (Figure 2). A decrease in the number of microorganisms was observed on the 30th day of the fermentation period. On the $60^{\text {th }}$ day, while the number
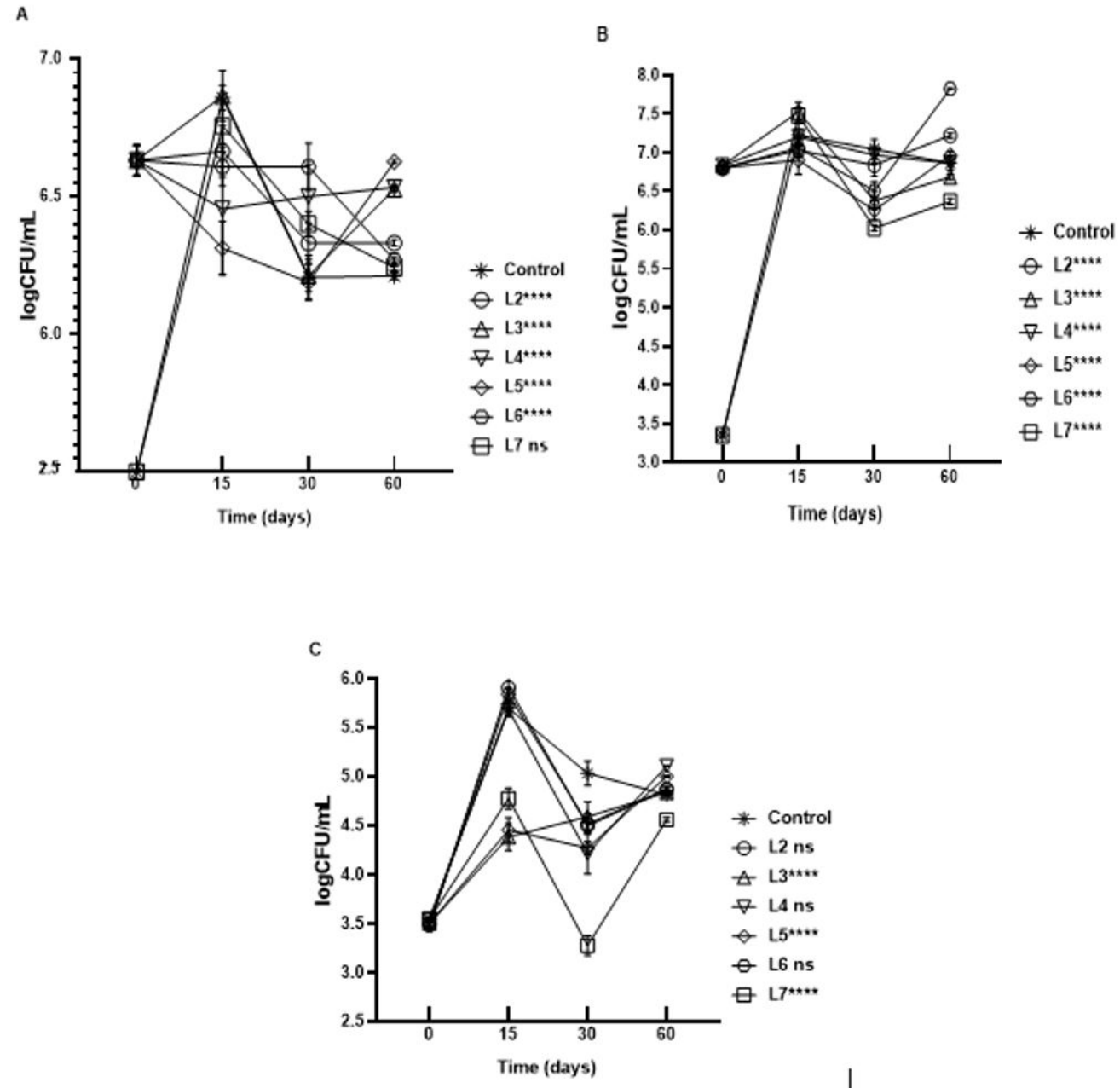

Figure 2. The changes in the LAB (A), total mesophilic aerobic bacteria (B) and yeast-mould (C) count in the pickled cabbage fermentation. 
of LABs was the same, it was found that there was an increase in the total number of mesophilic aerobic and yeast-moulds.

The total number of LABs in the L7 and control sample increased significantly in the first 15 days as seen in Figure 2. A great and substantial difference was observed when the total LAB count of the samples except the L7 sample was compared with the control sample ( $\mathrm{p}<0.0001)$. It was determined that the total LAB count decreased as of day 15 , up until day 30 , and remained at a constant rate until the $60^{\text {th }}$ day after the $30^{\text {th }}$ day.

The Colony-Forming Unit (CFU), which is a direct indicator of microbial species like bacteria, yeast, and LAB, has been used commonly for measurements in this field. According to the results of research on Kimchi and Chinese pickles, it was reported that the last CFU measurement remained almost the same regardless of inoculation (Cai et al., 2017). In our study, too, it was detected that the number of LABs remained stable on day 60 of fermentation. LABs could have a short metabolic cycle, acid resistance, and poor salt tolerance (Wouters et al., 2013). It is thought that the decrease in the total count of LABs in samples after the 15th day was due to these features.

The total mesophilic aerobic bacteria count in the control and L7 samples showed a rapid increase until the $15^{\text {th }}$ day (Figure 2). While a decrease was determined in all samples to the $30^{\text {th }}$ day, a significant increase was observed in the total mesophilic aerobic bacteria count in the L6 sample on the $60^{\text {th }}$ day. Furthermore, all samples were found a high and significant difference compared to the control sample $(\mathrm{p}<0$.0001). Previous studies found that the average number of colony grew in total aerobes as $10^{3}-10^{5} \mathrm{CFU} / \mathrm{g}$; and as $10^{7}-10^{8} \mathrm{CFU} / \mathrm{g}$ in LABs during the pickle fermentation (Peréz-Diaz et al., 2013). According to the results we obtained, the total number of LABs and mesophilic aerobic bacteria increased partially in the first 15 days of fermentation. It was observed that LABs and total mesophilic aerobic bacterial colonies decreased on the $30^{\text {th }}$ day of fermentation, whereas the average count of colonies increased on day 60 .
Until the $15^{\text {th }}$ day of fermentation, the total yeast-moulds count showed a rapid increase (Figure 2). While a decrease was observed in the number of yeast-moulds on day 30 in all pickle samples, it was observed that there was an increase again on day 60. A highly significant difference was found between the control sample and L3, L5, L7 samples ( $p<0.0001)$. Fungi have been recognized as undesirable microorganisms in the fermentation of sauerkraut (Wouters et al., 2013; Xiong et al., 2016). It is thought that it is very important that the Lactobacillus we used in the L3 and L5 pickle samples causes a decrease in the total count of yeast-moulds colonies with the progress of fermentation in the medium.

LABs and yeasts produce carbon dioxide by using the sugar in the fermentation and produce an anaerobic medium (Franco \& Perez-Diaz, 2012; Xiong et al., 2014). It is estimated that the decrease in the $\mathrm{pH}$ and the anaerobic medium, as well as high acidity, may lead to the destruction of fungi (Xiong et al., 2016). According to the results obtained in the present study of ours, it is considered that a high degree of acidity in the pickle sample L5 prevented the development of yeasts. The rapid decrease in the $\mathrm{pH}$ values at the start of the fermentation caused by LABs is of great importance for the quality a product and for the inhibition of unwanted bacteria that exist in cabbage (Viander et al., 2003). When starter cultures were added, a uniform decrease was observed in the $\mathrm{pH}$ (Beganovic et al., 2011). It was determined that Lactobacillus added as a starter culture to L4 and L5 pickle samples were effective on $\mathrm{pH}$ in our study.

\subsection{Biogenic amine content}

The amounts of tyramine, cadaverine, spermidine, histamine, and putrescine in traditional pickled cabbage made using starter culture were determined by HPLC (Table 1). On day 30 of fermentation, putrescine, histamine, tyramine, and spermidine were not detected in any of the pickle samples. L2, L3, L4, and L6 pickle samples for which we used Lactobacillus strains produced

Table 1. Biogenic amine amounts in the pickled cabbage fermentation.

\begin{tabular}{|c|c|c|c|c|c|c|c|}
\hline \multicolumn{8}{|c|}{ Concentration of biogenic amines $(\mathrm{mg} / \mathrm{L})$} \\
\hline \multicolumn{2}{|c|}{ Pickle samples } & \multirow{2}{*}{$\begin{array}{l}\text { Putrescine } \\
0.00 \pm 0.00\end{array}$} & \multirow{2}{*}{$\begin{array}{l}\text { Cadaverine } \\
0.00 \pm 0.00\end{array}$} & \multirow{2}{*}{$\begin{array}{l}\text { Histamine } \\
0.00 \pm 0.00\end{array}$} & \multirow{2}{*}{$\begin{array}{l}\text { Tyramine } \\
0.00 \pm 0.00\end{array}$} & \multirow{2}{*}{$\begin{array}{l}\text { Spermidine } \\
0.00 \pm 0.00\end{array}$} & \multirow{2}{*}{$\begin{array}{c}\begin{array}{c}\text { Total amount of } \\
\text { biogenic amines }\end{array} \\
0.00 \pm 0.00\end{array}$} \\
\hline Control & 30. day & & & & & & \\
\hline & 60. day & $13.17 \pm 0.20$ & $0.00 \pm 0.00$ & $0.00 \pm 0.00$ & $0.00 \pm 0.00$ & $0.00 \pm 0.00$ & $13.17 \pm 0.20$ \\
\hline \multirow[t]{2}{*}{ L2 } & 30. day & $0.00 \pm 0.00^{\mathrm{a}}$ & $0.00 \pm 0.00^{\mathrm{a}}$ & $0.00 \pm 0.00^{\mathrm{a}}$ & $0.00 \pm 0.00^{\mathrm{a}}$ & $0.00 \pm 0.00^{\mathrm{a}}$ & $0.00 \pm 0.00^{\mathrm{a}}$ \\
\hline & 60. day & $9.38 \pm 0.15^{\mathrm{e}}$ & $0.00 \pm 0.00^{\mathrm{a}}$ & $5.53 \pm 0.18^{\mathrm{e}}$ & $3.51 \pm 0.27^{\mathrm{e}}$ & $0.00 \pm 0.00^{\mathrm{a}}$ & $18.41 \pm 0.30^{\mathrm{e}}$ \\
\hline \multirow[t]{2}{*}{ L3 } & 30. day & $0.00 \pm 0.00^{\mathrm{a}}$ & $4.90 \pm 0.19^{\mathrm{e}}$ & $0.00 \pm 0.00^{\mathrm{a}}$ & $0.00 \pm 0.00^{\mathrm{a}}$ & $0.00 \pm 0.00^{\mathrm{a}}$ & $4.90 \pm 0.19^{e}$ \\
\hline & 60. day & $6.68 \pm 0.24^{\mathrm{e}}$ & $0.00 \pm 0.00^{\mathrm{a}}$ & $4.75 \pm 0.15^{\mathrm{e}}$ & $4.03 \pm 0.11^{\mathrm{e}}$ & $0.00 \pm 0.00^{\mathrm{a}}$ & $15.45 \pm 0.28^{\mathrm{e}}$ \\
\hline \multirow[t]{2}{*}{$\mathrm{L} 4$} & 30. day & $0.00 \pm 0.00^{\mathrm{a}}$ & $0.00 \pm 0.00^{\mathrm{a}}$ & $0.00 \pm 0.00^{\mathrm{a}}$ & $0.00 \pm 0.00^{\mathrm{a}}$ & $0.00 \pm 0.00^{\mathrm{a}}$ & $0.00 \pm 0.00^{\mathrm{a}}$ \\
\hline & 60. day & $5.19 \pm 0.25^{\mathrm{e}}$ & $0.00 \pm 0.00^{\mathrm{a}}$ & $4.82 \pm 0.14^{\mathrm{e}}$ & $0.00 \pm 0.00^{\mathrm{a}}$ & $0.00 \pm 0.00^{\mathrm{a}}$ & $10.00 \pm 0.11^{\mathrm{e}}$ \\
\hline \multirow[t]{2}{*}{ L5 } & 30. day & $0.00 \pm 0.00^{\mathrm{a}}$ & $4.99 \pm 0.17^{\mathrm{e}}$ & $0.00 \pm 0.00^{\mathrm{a}}$ & $0.00 \pm 0.00^{\mathrm{a}}$ & $0.00 \pm 0.00^{\mathrm{a}}$ & $4.99 \pm 0.17^{\mathrm{e}}$ \\
\hline & 60. day & $11.30 \pm 0.31^{\mathrm{d}}$ & $0.00 \pm 0.00^{\mathrm{a}}$ & $5.32 \pm 0.24^{\mathrm{e}}$ & $0.00 \pm 0.00^{\mathrm{a}}$ & $0.00 \pm 0.00^{\mathrm{a}}$ & $16.62 \pm 0.06^{\mathrm{e}}$ \\
\hline \multirow[t]{2}{*}{ L6 } & 30. day & $0.00 \pm 0.00^{\mathrm{a}}$ & $6.10 \pm 0.17^{e}$ & $0.00 \pm 0.00^{\mathrm{a}}$ & $0.00 \pm 0.00^{\mathrm{a}}$ & $0.00 \pm 0.00^{\mathrm{a}}$ & $6.10 \pm 0.17^{e}$ \\
\hline & 60. day & $9.22 \pm 0.15^{\mathrm{e}}$ & $0.00 \pm 0.00^{\mathrm{a}}$ & $6.35 \pm 0.16^{\mathrm{e}}$ & $3.44 \pm 0.10^{\mathrm{e}}$ & $0.00 \pm 0.00^{\mathrm{a}}$ & $19.01 \pm 0.21^{\mathrm{e}}$ \\
\hline \multirow[t]{2}{*}{ L7 } & 30. day & $0.00 \pm 0.00^{\mathrm{a}}$ & $5.48 \pm 0.35^{\mathrm{e}}$ & $0.00 \pm 0.00^{\mathrm{a}}$ & $0.00 \pm 0.00^{\mathrm{a}}$ & $0.00 \pm 0.00^{\mathrm{a}}$ & $5.48 \pm 0.35^{\mathrm{e}}$ \\
\hline & 60. day & $12.52 \pm 0.38^{\mathrm{a}}$ & $0.00 \pm 0.00^{\mathrm{a}}$ & $0.00 \pm 0.00^{\mathrm{a}}$ & $3.67 \pm 0.16^{\mathrm{e}}$ & $0.00 \pm 0.00^{\mathrm{a}}$ & $16.19 \pm 0.22^{\mathrm{e}}$ \\
\hline
\end{tabular}

a: ns, b: ${ }^{*}$, : $^{* *}, \mathrm{~d}:{ }^{* * *}$ and $\mathrm{e}:{ }^{* * * *}$ 
a small amount of putrescine on day 60 and showed a highly significant difference $(\mathrm{p}<0.0001)$.

Since cadaverine was detected in the L3, L5, L6, and L7 samples on day 30 of fermentation, a high and significant difference was determined $(\mathrm{p}<0.0001)$. No cadaverine and spermidine were detected in any sample on day 60 of fermentation. Lack of histamine of samples L7 and in the control in which Lactobacillus strains were not used showed a highly significant difference $(p<0.0001)$. When considered in terms of tyramine, it was detected in L2, L3, L6, and L7 samples, and the difference was significant in this respect $(\mathrm{p}<0.0001)$.

When the total amounts of 5 different BAs were evaluated in our study, it was determined that there was a highly significant difference in the L3, L5, L6, and L7 samples on the $30^{\text {th }}$ day $(p<0.0001)$. It was observed that a significant difference in the L4 sample where the L. plantarum strain was used on day 60 of fermentation because the BA amount was at the minimum level $(p<0.0001)$. In the other pickle samples, the presence of $B A$ being at higher amounts than the control sample indicated a high and significant difference $(\mathrm{p}<0.0001)$.

In another study, it was determined that biogenic amines like putrescine, cadaverine, and tyramine were more dominant during the sauerkraut fermentation (Wu et al., 2014). In our study, on the other hand, histamine was also observed in addition to these biogenic amines. The use of different starter-cultures could impact the formation of BA in a variety of ways. Furthermore, as well as BA-producing strains, enzymes are also present which have negative decarboxylase activities or which can oxidize BA in foods (La Gioia et al., 2011). It has been previously found that BA content in the of the self-fermented control sauerkraut sample compared to inoculated samples to be higher (Sahu et al., 2016). It was detected that $L$. plantarum strains can be used to degrade and decrease biogenic amines in different plant-based fermented products (Wu et al., 2014). The presence of the least amount of BA in the L4 sample to which L. plantarum was added as a starter culture shows that there is a similarity with the studies mentioned above. In spontaneous fermentation and inoculated fermentation, long-term storage and external factors can significantly affect the formation of BA in food products (Majcherczyk \& Surówka, 2019). It was found that the quantity of BA increased with the progress of fermentation in our study.

When BAs are too high in food, they can be converted into toxic metabolites responsible for serious health problems because they inhibit human detoxification ability (Anderson, 2008). For some BAs commonly encountered in fermented products such as pickles, toxic limits have been determined as $100-800 \mathrm{mg} / \mathrm{kg}$ tyramine, $50-100 \mathrm{mg} / \mathrm{kg}$ histamine, and $100-200 \mathrm{mg} / \mathrm{kg}$ total BA (Nout, 1994). In our study, it was determined that the amount of histamine, tyramine, and a total BA in all pickle samples were under toxic value that affected the health of humans.

\subsection{Metabolite content}

The quantity of lactate, pyruvate, ethanol, acetic acid, acetoin, 2.3-butanediol, and $\mathrm{H}_{2} \mathrm{O}_{2}$ metabolites, which are fermentation products, in pickle samples are given in Table 2. It was found that the amount of pyruvate determined on day
60 of fermentation in the pickle samples (L2, L3, L4, L5, and L6) using starter culture was approximately more than twice the value determined on day 30 .

The highest amount of lactate was observed in the L4 sample on day 60 of fermentation. The lactate amount was not determined on day 30 of fermentation in any of the pickle samples. It was determined that the amount of acetic acid was close to each other on day 30 in all samples. On day 60, L6 and L7 samples produced the highest amount of acetic acid, while the L3 sample produced the least amount, showing a great difference ( $\mathrm{p}$ 0.0001). During the fermentation, the presence of hydrogen peroxide was observed to be similar within all of the pickle samples. It was also determined that the ethanol amount that was detected on day 60 decreased significantly compared to that of the $30^{\text {th }}$ day. It was determined that the ethanol synthesis between the samples was close to each other during the fermentation. Acetoin was not detected in L6 and L7 samples on the $30^{\text {th }}$ day. While the acetoin amount decreased in the L1, L3, and L5 samples on day 60 of fermentation, it increased in L2, L4, L6, and L7 samples. In addition, 2.3-butanediol was not synthesized in any of the samples on the $30^{\text {th }}$ day; however, it was synthesized at excessive amounts on the $60^{\text {th }}$ day. The L4 sample showed a significant difference by synthesizing the highest amount of 2.3-butanediol $(p<0.0001)$. While there was no significant difference between the samples in the total amount of metabolites on the $30^{\text {th }}$ day, it was found that there was a significant difference in the L4 and L6 samples on the $60^{\text {th }}$ day ( $\mathrm{p} 0.0002$ ). It was determined that on the $60^{\text {th }}$ day of fermentation, the total amount of metabolites in all samples increased compared to the $30^{\text {th }}$ day.

The starter cultures that were used in sauerkraut affected the amount of lactic acid directly (Xiong et al., 2014). It was reported that the lactic acid amount in the cabbage was higher in the first stage of the fermentation, and in the later stages, it was lower (Xiong et al., 2016). This result may stem from two reasons, the first one is that the first stage of the fermentation is dominated by hetero-fermentative LAB, which is weak in acid production, and the second is that some microorganisms in the brine cannot produce lactic acid by using nutrients in the medium (Franco \& Perez-Diaz, 2012). As seen in Table 2, the lack of detection of lactate on day 60 of fermentation supports this situation. LABs convert the pyruvate that they form by fermentation of glucose into lactate with lactate dehydrogenase (Liu et al., 2006). The lactate formed during glycolysis is used to reduce the equivalent amount of pyruvate (De Vos \& Hugenholtz, 2004). The amount of lactate we determined in our study confirms the result that the equivalent amount of pyruvate is used. Because, as seen in the table, while lactate was not detected on the $60^{\text {th }}$ day in the pickle samples, it was observed that the amount of pyruvate increased in the other samples except for the L7 sample.

In a previous study, it was determined that fermentation by-products such as ethanol and acetoin are produced by LABs (Tsuji et al., 2013). In our study, acetoin was detected in L6 and L7 samples on the other days except for on day 30 of fermentation. It was also observed that ethanol was present during the fermentation.

Since 2.3-butanediol is an important chemical nutritional stock with economic value, its biotechnological production is 


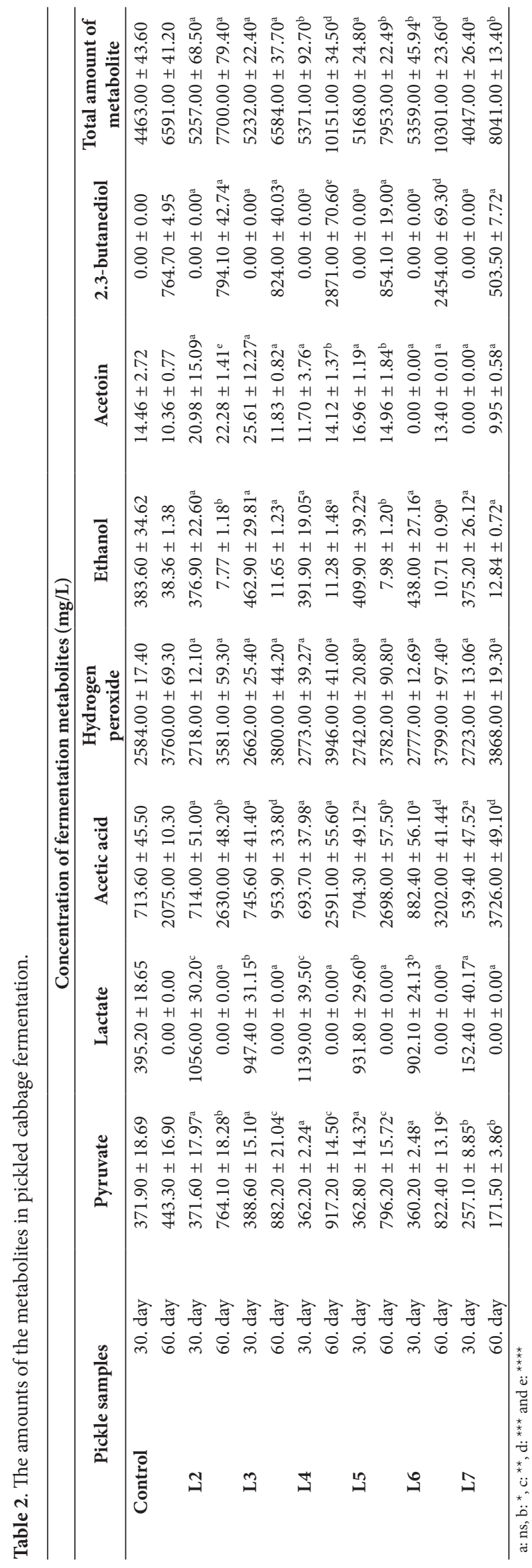


important. 2.3-butanediol dehydrogenation results in diacetyl and acetoin (Gaspar et al., 2013). While 2.3-butanediol was not found on day 30 of fermentation, the highest amount was detected in L4 and L6 samples on the $60^{\text {th }}$ day. Most LABs have the flavoprotein oxidase enzyme which ensured that $\mathrm{H}_{2} \mathrm{O}_{2}$ is created in the company of lactate, oxygen, $\mathrm{NADH}$, and pyruvate (Schnürer \& Magnusson, 2005). As Table 2 indicates, the amount of $\mathrm{H}_{2} \mathrm{O}_{2}$ in all samples was determined to be half of the total metabolites during fermentation. LABs yield compounds having antimicrobial activity, together with lactic and acetic acid that causes $\mathrm{pH}$ decrease (Lind et al., 2005). In addition, propionic acid, formic acid, acetone, $\mathrm{H}_{2} \mathrm{O}_{2}$, and some other substances like diacetyl are also created (Tolonen et al., 2004). Examining the data collected in the current study, it was ascertained that the metabolites detected in the pickle samples affect both the $\mathrm{pH}$ of the medium and also have antimicrobial effects on the microorganisms in the same medium.

\section{Conclusion}

In our study, 5 different starter cultures (L. plantarum 8, L. plantarum 46, L. plantarum 61, L. pentosus and L. paraplantarum) added to sauerkrauts that were prepared with traditional methods, and were compared with the fermentation profiles of the pickle samples to which starter cultures were added. The pickle samples to which Lactobacillus strains were added showed significant differences in terms of titratable acidity. The $\mathrm{pH}$ values of the samples L4 and L5 showed significant differences compared to the control sample. It was observed that there were significant decreases in the total number of yeast-mould colony and mesophilic aerobic bacteria counts in sample L7 during fermentation period. In the pickle sample L4, L. plantarum was added as the starter-culture, the BA presence was detected at the minimum amount. When the amounts of BAs were evaluated alone or as total, it was determined that these amounts were under any toxic level which may impact human health. Also observed was, the BAs were synthesized as the fermentation period increased. Lactate determined on day 30 of the fermentation, and 2.3-butanediol was determined on day 60 of the fermentation. It was observed that the amount of acetic acid increased and ethanol decreased as the fermentation time increased. It was found L4, in which L. plantarum 61 was used, showed superior fermentation profile than other samples. However, the effects of the microbial flora and metabolite production that are effective on the fermentation of pickled cabbage produced with traditional methods have not yet been fully elucidated. Therefore, it is of crucial importance that studies are conducted to observe the activities of L. plantarum, which show a good fermentation profile, or the enzymes that are effective in LAB metabolism. The results that are presented in this study are of great importance in that the L4 pickled cabbage sample that was inoculated with L. plantarum 61 starter culture synthesizes the metabolites, which are flavoring compounds, and has low total biogenic amines. Investigating the enzyme activity, which effectively metabolise LABs, like this isolate, and conducting more detailed studies are of great importance. By considering these results, a great contribution may be made to the high-quality traditional pickled production.

\section{References}

Adams, M. (1990). Topical aspects of fermented foods. Trends in Food Science \& Technology, 1, 140-144. http://dx.doi.org/10.1016/09242244(90)90111-B.

Alan, D. (2015). Determination of molecular identification and plasmid content of Lactobacillus pentosus and Lactobacillus paraplantarum strains of pickle from natural. Kahramanmaraş: Kahramanmaraş Sütçü Imam University.

Alan, Y., Topalcengiz, Z., \& Dığrak, M. (2018). Biogenic amine and fermentation metabolite production assessments of Lactobacillus plantarum isolates for naturally fermented pickles. LebensmittelWissenschaft + Technologie, 98, 322-328. http://dx.doi.org/10.1016/j. lwt.2018.08.067.

Alan, Y. (2019). Culture fermentation of Lactobacillus in traditional pickled gherkins: microbial development, chemical, biogenic amine and metabolite analysis. Journal of Food Science and Technology, 56(8), 3930-3939. http://dx.doi.org/10.1007/s13197-019-03866-8. PMid:31413418.

Anderson, A. K. (2008). Biogenic and volatile amine-related qualities of three popular fish species sold at Kuwait fish markets. Food Chemistry, 107(2), 761-767. http://dx.doi.org/10.1016/j.foodchem.2007.08.094.

Beganovic, J., Pavunc, A. L., Gjuracic, K., Spoljarec, M., Suskovic, J., \& Kos, B. (2011). Improveproduction with probiotic strain Lactobacillus plantarum L4 and Leuconostoc mesenteroides LMG 7954. Journal of Food Science, 76(2), 124-129. http://dx.doi.org/10.1111/j.17503841.2010.02030.x. PMid:21535775.

Cai, J., Chi, Y., Wang, D., Tang, Y., Jin, L., \& Zhang, Q. (2017). Microflora and characteristics of main spoilage microorganisms in putrid Sichuan pickle. Food Science and Technology, 1, 279-283.

De Vos, W. M., \& Hugenholtz, J. (2004). Engineering metabolic highways in Lactococci and other lactic acid bacteria. Trends in Biotechnology, 22(2), 72-79. http://dx.doi.org/10.1016/j.tibtech.2003.11.011. PMid:14757041.

Di Cagno, R., Coda, R., De Angelis, M., \& Gobbetti, M. (2013). Exploitation of vegetables and fruits through lactic acid fermentation. Food Microbiology, 33(1), 1-10. http://dx.doi.org/10.1016/j.fm.2012.09.003. PMid:23122495.

Franco, W., \& Perez-Diaz, I. M. (2012). Role of selected oxidative yeasts and bacteria in cucumber secondary fermentation associated with spoilage of the fermented fruit. Food Microbiology, 32(2), 338-344. http://dx.doi.org/10.1016/j.fm.2012.07.013. PMid:22986199.

Gaspar, P., Carvalho, A. L., Vinga, S., Santos, H., \& Neves, A. R. (2013). From physiology to systems metabolic engineering for the production of biochemicals by lactic acid bacteria. Biotechnology Advances, 31(6), 764-788. http://dx.doi.org/10.1016/j.biotechadv.2013.03.011. PMid:23567148.

Jo, S. Y., Choi, E. A., Lee, J. J., \& Chang, H. C. (2015). Characterization of starter kimchi fermented with Leuconostoc kimchii GJ2 and its cholesterol-lowering effects in rats fed a high-fat and high-cholesterol diet. Journal of the Science of Food and Agriculture, 95(13), 2750-2756. http://dx.doi.org/10.1002/jsfa.7018. PMid:25425317.

La Gioia, F., Rizzotti, L., Rossi, F., Gardini, F., Tabanelli, G., \& Torriani, S. (2011). Identification of a tyrosine decarboxylase gene (tdcA) in Streptococcus thermophilus 1TT45 and analysis of its expression and tyramine production in milk. Applied and Environmental Microbiology, 77(3), 1140-1144. http://dx.doi.org/10.1128/AEM.0192810. PMid:21131517.

Lind, H., Jonsson, H., \& Schnurer, J. (2005). Antifungal effect of dairy propionibacteria-contribution of organic acids. International Journal 
of Food Microbiology, 98(2), 157-165. http://dx.doi.org/10.1016/j. ijfoodmicro.2004.05.020. PMid:15681043.

Liu, Q., Wu, J. E., Lim, Z. Y., Aggarwal, A., Yang, H., \& Wang, S. (2017). Evaluation of the metabolic response of Escherichia coli to electrolysed water by $1 \mathrm{H}$ NMR spectroscopy. Lebensmittel-Wissenschaft + Technologie, 79, 428-436. http://dx.doi.org/10.1016/j.lwt.2017.01.066.

Liu, S., Nichols, N. N., Dien, B. S., \& Cotta, M. A. (2006). Metabolic engineering of a Lactobacillus plantarum double ldh knockout strain for enhanced ethanol production. Journal of Industrial Microbiology \& Biotechnology, 33(1), 1-7. http://dx.doi.org/10.1007/s10295-0050001-3. PMid:16193282.

Maijala, R., Nurmi, E., \& Fischer, A. (1995). Influence of processing temperature on the formation of biogenic amines in dry sausages. Meat Science, 39(1), 9-22. http://dx.doi.org/10.1016/0309-1740(95)800034. PMid:22059759.

Majcherczyk, J., \& Surówka, K. (2019). Effects of onion or caraway on the formation of biogenic amines during sauerkraut fermentation and refrigerated storage. Food Chemistry, 298, 125083. http://dx.doi. org/10.1016/j.foodchem.2019.125083. PMid:31261001.

Nilchian, Z., Rahimi, E., Razavi, S., \& Momeni Shahraki, M. (2016). Isolation and identification of $L$. plantarum from Iranian fermented cucumbers by conventional culture and PCR methods. Journal of Food Biosciences and Technology, 6(1), 69-76.

Nout, M. (1994). Fermented foods and food safety. Food Research International, 27(3), 291-298. http://dx.doi.org/10.1016/09639969(94)90097-3.

Peréz-Diaz, I., Breidt, F., Buescher, R., Arroyo-López, F., Jiménez-Diaz, R., Garrido-Fernández, A., \& Johanningsmeire, S. (2013). Fermented and acidified vegetables (4th ed.). Washington, DC: American Public Health Association.

Pistarino, E., Aliakbarian, B., Casazza, A. A., Paini, M., Cosulich, M. E., \& Perego, P. (2013). Combined effect of starter culture and temperature on phenolic compounds during fermentation of Taggiasca black olives. Food Chemistry, 138(2-3), 2043-2049. http://dx.doi. org/10.1016/j.foodchem.2012.11.021. PMid:23411341.

Plengvidhya, V., Breidt, F. J. Jr, Lu, Z., \& Fleming, H. P. (2007). DNA fingerprinting of lactic acid bacteria in sauerkraut fermentations. Applied and Environmental Microbiology, 73(23), 7697-7702. http:// dx.doi.org/10.1128/AEM.01342-07. PMid:17921264.

Sáez, G. D., Flomenbaum, L., \& Zárate, G. (2018). Lactic acid bacteria from Argentinean fermented foods: isolation and characterization for their potential use as starters for fermentation of vegetables. Food Technology and Biotechnology, 56(3), 398-410. http://dx.doi. org/10.17113/ftb.56.03.18.5631. PMid:30510483.

Sahu, L., Panda, S. K., Paramithiotis, S., Zdolec, N., \& Ray, R. C. (2016). Fermented foods, Part I: Biochemistry and biotechnology. In D. Montet \& R. C. Ray (Ed.), Biogenic amines in fermented foods: overview (Chap. 17, pp. 303-317). USA: CRC Press.

Schnürer, J., \& Magnusson, J. (2005). Antifungal lactic acid bacteria as biopreservatives. Trends in Food Science \& Technology, 16(1-3), 70-78. http://dx.doi.org/10.1016/j.tifs.2004.02.014.
Tolonen, M., Rajaniemi, S., Pihlava, J. M., Johansson, T., Saris, P. E., \& Ryhänen, E. L. (2004). Formation of nisin, plant-derived biomolecules and antimicrobial activity in starter culture fermentations of sauerkraut. Food Microbiology, 21(2), 167-179. http://dx.doi.org/10.1016/S07400020(03)00058-3.

Trail, A. C., Fleming, H. P., Young, C. T., \& McFeeters, R. F. (1996). Chemical and sensory characterization of commercial sauerkraut. Journal of Food Quality, 19(1), 15-30. http://dx.doi.org/10.1111/j.1745-4557.1996. tb00402.x.

Tsuji, A., Okada, S., Hols, P., \& Satoh, E. (2013). Metabolic engineering of Lactobacillus plantarum for succinic acid production through activation of the reductive branch of the tricarboxylic acid cycle. Enzyme and Microbial Technology, 53(2), 97-103. http://dx.doi. org/10.1016/j.enzmictec.2013.04.008. PMid:23769309.

Viander, B., Mäki, M., \& Palva, A. (2003). Impact of low salt concentration, salt quality on natural large-scale sauerkraut fermentation. Food Microbiology, 20(4), 391-395. http://dx.doi.org/10.1016/S07400020(02)00150-8.

Wouters, D., Bernaert, N., Conjaerts, W., Van Droogenbroeck, B., De Loose, M., \& De Vuyst, L. (2013). Species diversity, community dynamics, and metabolite kinetics of spontaneous leek fermentations. Food Microbiology, 33(2), 185-196. http://dx.doi.org/10.1016/j. fm.2012.09.016. PMid:23200651.

Wu, C., Zheng, J., Huang, J., \& Zhou, R. (2014). Reduced nitrite and biogenic amine concentrations and improved flavor components of Chinese sauerkraut via co-culture of Lactobacillus plantarum and Zygosaccharomyces rouxii. Annals of Microbiology, 64(2), 847-857. http://dx.doi.org/10.1007/s13213-013-0724-8.

Xiong, T., Li, J., Liang, F., Wang, Y., Guan, Q., \& Xie, M. (2016). Effects of salt concentration on Chinese sauerkraut fermentation. Lebensmittel-Wissenschaft + Technologie, 69, 169-174. http://dx.doi. org/10.1016/j.lwt.2015.12.057.

Xiong, T., Li, X., Guan, Q., Peng, F., \& Xie, M. (2014). Starter culture fermentation of Chinese sauerkraut: growth, acidification and metabolic analyses. Food Control, 41, 122-127. http://dx.doi. org/10.1016/j.foodcont.2013.12.033.

Yoon, K. Y., Woodams, E. E., \& Hang, Y. D. (2006). Production of probiotic cabbage juice by lactic acid bacteria. Bioresource Technology, 97(12), 1427-1430. http://dx.doi.org/10.1016/j.biortech.2005.06.018. PMid:16125381.

Zhao, D., Du, R. P., Ping, W. X., \& Ge, J. P. (2018). Lactobacillus paracasei HD1.7 used as a starter modulates the bacterial community and metabolome profile during fermentation of Chinese cabbage. Letters in Applied Microbiology, 67(4), 411-419. http://dx.doi.org/10.1111/ lam.13056. PMid:30035816.

Zubaidah, E., Susanti, I., Yuwono, S. S., Rahayu, A. P., Srianta, I., \& Blanc, P. J. (2020). Effect of Lactobacillus plantarum and Leuconostoc mesenteroides starter cultures in lower salt concentration fermentation on the sauerkraut quality. Food Research, 4(4), 1038-1044. http:// dx.doi.org/10.26656/fr.2017.4(4).029. 